\title{
DISCUTINDO A ESCRITA ESCOLAR PELO VIÉS PRAGMÁTICO: ALGUMAS CONSIDERAÇÕES
}

Yara Fernanda Novatzki é formada em Licenciatura em Letras Português-Inglês pela Universidade Estadual de Ponta Grossa (UEPG) e atualmente é mestranda em Linguagem, Identidade e Subjetividade pela mesma instituição.

E-mail: yarafernandan@hotmail.com

Resumo: Este artigo traz uma discussão teórica com o objetivo de refletirmos sobre como as transformações ocorridas no português brasileiro, notadamente na língua(gem) escrita, afetam a compreensão desses termos atualmente. Partimos de um breve apanhado histórico para abordarmos algumas contradições e consensos ocorridos dentro dos muros escolares no viés da pragmática linguística, Pinto (2012, 2014), Rajagopalan (2010, 2013), Kramsch (2014), entre outros.

\begin{abstract}
This article presents a theoretical discussion with the goal to reflect about how transformations occurred in Brazilian Portuguese, notably writing language, affect the understanding of these terms currently. We start with a brief historical overview to address some contradictions and consensus that occurred within the school walls in the bias of linguistic pragmatics, Pinto (2012, 2014), Rajagopalan (2010, 2013), Kramsch (2014), among others authors.
\end{abstract}

\section{1) Palavras Iniciais...}

Ao pararmos para pensar no quanto as relações estabelecidas com o ensino escolar se alteraram, vamos notar que intensas e rápidas transformações de naturezas política, econômica, social, cultural e tecnológica também podem ser observadas na sociedade. Nesses mais de 500 anos de história, podemos perceber que a situação linguística no Brasil é marcada por inúmeras ocorrências de contato linguístico desenvolvidas desde que os jesuítas aqui se estabeleceram. Esse fato pode ser observado, inclusive, diante da vinda e da permanência do Marquês de Pombal com outros inúmeros portugueses, os quais traziam consigo o seu modo de falar (SILVA, 2004).

Diante de tamanha heterogeneidade presente na língua(gem $)^{1}$, devemos notar que os modos de se compreender a escrita e a língua(gem) naquele momento histórico sofreram alterações. No entanto, em alguns contextos, tais modificações parecem ser disfarçadas diante das exigências advindas desde que o português se tornou vigente aqui no Brasil, por exemplo, por meio do uso da gramática normativa na escola, seja na escola constituída naquele contexto histórico, como na atual, entendida como o modelo canônico de reprodução da língua(gem).

Segundo o que preveem os Parâmetros Curriculares Nacionais (PCN), o ensino da língua(gem), e em decorrência o da escrita, deve ir muito além de ensinar regras e listas de palavras, como comumente vemos na gramática normativa. Para os PCN,

\footnotetext{
1 A utilização deste termo ocorrerá sempre que nos referirmos ao entendimento abordado por Signorini (1998), que compreende a língua(gem) de modo amplo, pois leva em conta, além dos interlocutores, também a ação desenvolvida nas situações de interação comunicativa. No entanto, salientamos que quando nos referirmos ao termo língua, o sentido adotado é como o proposto por Faraco (2008, p. 74), que nos diz: “qualquer língua é sempre heterogênea, ou seja, constituída por um conjunto de variedades (por um conjunto de normas). Não há, como muitas vezes imagina o senso comum, a língua de um lado, e, de outro, as variedades. A língua é, em si, um conjunto de variedades”.
} 
toda educação verdadeiramente comprometida com o exercício da cidadania precisa criar condições para o desenvolvimento da capacidade de uso eficaz da linguagem que satisfaça necessidades pessoais - que podem estar relacionadas às ações efetivas do cotidiano, à transmissão e busca de informação, ao exercício da reflexão. (BRASIL, 1998, p. 30).

Dessa forma, é necessário ensinarmos aos alunos a língua viva, aquela que de fato acontece em nosso meio e em nossas diversas situações de uso, a fim de que os alunos possam vivenciá-la e, assim, consigam aproximar a escrita, utilizada em inúmeros contextos, de suas próprias realidades. Logo, os alunos se tornarão capazes de utilizar eficazmente a língua(gem) nos mais variados contextos, pois, conforme nos diz Ferrarezi Jr (2014, p. 62), "será justamente o aprendizado satisfatório da linguagem, em todas as suas modalidades e já nas séries iniciais, que permitirá ao aluno todo o acesso adequado aos demais conhecimentos em sua vida escolar".

Porém, mesmo que muitas vezes se reconheça tal necessidade, diante da visão de língua heterogênea, "os estudos demonstram que, na prática cotidiana, não só pedagógica, mas também social e ideológica, figura-se preponderantemente a visão homogênea, abalizada pela norma padrão" (CORREA, 2014, p. 19). Essa pseudoideia de língua única, idealizada no imaginário das pessoas (CORREA, 2014) acaba por influenciar significativamente nas escolhas e nas ações assumidas diante da sociedade.

Nesse sentido, podemos perceber que nos falta ainda um pouco de autonomia para desenvolvermos um trabalho que favoreça a diversidade presente na língua(gem), em que a importância seja dada aos dois âmbitos, o que defende a heterogeneidade e o que defende a homogeneidade, a fim de que suas especificidades possam ser discutidas e não se tenha somente uma visão restrita do que está presente na língua(gem), ou seja, o que acontece na teoria deve aproximar-se da prática e vice-versa, de modo que as diversas situações sociolinguísticas ${ }^{2}$ possam ser valorizadas.

Levando em conta a discussão acima, propusemos um estudo ${ }^{3}$, a fim de que possamos refletir sobre os modos como se têm pensado a língua(gem) e a escrita desenvolvidas nas salas de aula. Para tanto, buscamos subsídios em autores como Austin (1962), Kramsch (2012, 2014), Pinto (2006, 2012, 2013, 2014), Rajagopalan (2003, 2013, 2014), entre outros que problematizam as questões de língua(gem) e escrita na sala de aula por meio do viés pragmático.

\footnotetext{
${ }^{2}$ Entendemos que situações sociolinguísticas são aquelas "em que a heterogeneidade da língua fica mascarada sob a pseudoideia de língua única como identificadora de um povo, um país, um território, uma nação". (CORREA, 2014, P. 20).

${ }^{3}$ Este estudo faz parte de uma dissertação de Mestrado em fase de desenvolvimento, o qual tem como título: "Para compreender melhor as atuais práticas de escrita escolar do aluno no $5^{\circ}$ e $6^{\circ}$ ano do ensino fundamental".
} 


\section{2) Língua(gem) e Escrita: alguns pontos de embate e questionamento}

Ao observarmos as ações desenvolvidas na história da constituição do português do Brasil, podemos notar o modo como as políticas linguísticas ${ }^{4}$ se desenvolveram aqui, sendo o decreto do Marquês de Pombal um desses exemplos.

Por meio desse decreto, foi estabelecido que o português fosse a língua única aqui no Brasil. As escolhas realizadas para este fim foram desempenhadas pelo Estado, o qual detinha o poder para dominar e escolher aquilo que era entendido como sendo o melhor para toda a população, nem que diante dessa postura uns fossem mais privilegiados que outros.

A relação de poder que se estabeleceu evidencia, portanto, que a língua(gem) carrega consigo um imenso poder de dominação e de representação perante a sociedade e os sujeitos, pois a língua, segundo Rajagopalan (2003, p. 93), "é muito mais que um simples código ou instrumento de comunicação. Ela é, antes de qualquer coisa, uma das principais marcas de identidade de uma nação, de um povo. Ela é uma bandeira política".

Desse modo, podemos observar que uma hierarquia se estabeleceu e se estabelece por meio da língua(gem), na qual quem a domina de modo mais coerente, agindo segundo as normas estabelecidas pelo Estado, ou diante de outras instituições que carregam consigo o poder e, ainda, diante do "bem falar e escrever", recebe maior valorização em relação aos que têm pouco acesso ao conhecimento esperado, visto que somos julgados por meio daquilo que somos e dos modos como estamos inseridos na sociedade ou em determinados âmbitos, sejam eles quais forem.

Essa valorização foi reforçada a partir do momento em que a escrita tida como a correta, como a coerente, aquela que está dentro dos padrões previstos tornou-se consagrada, ou seja, a partir da elevação do status da escrita, a fala recebeu menos importância e foi tendo menos valorização, pois era por meio da escrita que havia a possibilidade de fixar no papel tudo o que era realizado por meio da oralidade. Assim, a escrita passou a ser vista como um forte mecanismo de poder. Além desse fato, o idealismo de uma língua única contribuiu e foi reforçado quando se introduziu o uso da gramática normativa da língua portuguesa, limitando, dessa forma, também a escrita a uma forma padrão e única.

Sabemos que a introdução das primeiras gramáticas da língua portuguesa se deu por volta do século XVI, "a partir de 1536, quando Portugal vivia ainda um período de auge político como a primeira potência marítima e mercantil do mundo moderno" (FARACO, 2008, p. 142), mas foi a partir do século XX que a ortografia do português passou a ter estabilidade, época em que "a questão ortográfica se torna um assunto de

\footnotetext{
${ }^{4} \mathrm{O}$ termo "política linguística é entendido nesse trabalho como sendo "a arte de conduzir reflexões em torno de línguas específicas, com o intuito de conduzir ações concretas de interesse público relativos à(s) língua(s) que importam para o povo de uma nação, de um estado ou ainda, instâncias transnacionais maiores" (RAJAGOPALAN, 2013. p. 21), tendo como objetivo interferir nos fatos linguísticos, ou seja, o termo é utilizado para se referir às diversas atividades de caráter político que giram em torno da língua.
} 
Estado e se criam leis fixando a ortografia oficial" (FARACO, 2008, p. 143), ou seja, a partir de então regras ortográficas definidas precisavam ser seguidas.

Nessa época, a gramática deixou de ser suplemento para os falantes interessados em aperfeiçoar o domínio de sua língua materna e passou a ser o ponto de partida para se chegar a conhecer a língua que lhes era, de fato, estrangeira, visto que apresentava muitas diferenças entre o falar e o escrever (FARACO, 2008). Sendo assim, o modelo pedagógico empregado tornou-se extremamente normativo, prevalecendo, então, a ideia do certo e do errado, desconsiderando-se, dessa forma, tudo aquilo que era diferente do padrão.

Atualmente, mesmo vivendo em um mundo ultrassaturado de informações (PORCHEDDU, 2009) e, diante das inúmeras transformações ocorridas, em que, "num mundo globalizado como o de hoje, as línguas estão sofrendo influências mútuas numa escala sem precedentes" (RAJAGOPALAN, 2003, p.68), vemos que, ainda assim, a ideia do monolinguismo se faz presente, principalmente nas escolas, lugar em que se perpetua o discurso da homogeneização. Essa voz incessantemente reiterada acaba por tornar a noção de língua insustentável, pois não condiz satisfatoriamente com as necessidades vivenciadas contemporaneamente, já que estamos constantemente diante de novas formas de língua(gem) e de escrita.

Em relação à escrita, indo ao encontro das ideias de Ferrarezi Jr (2014), precisamos, de uma vez por todas,

desvincular a ideia da 'escrita na escola' da ideia da 'redação escolar'. A escrita na escola precisa ser a escrita-na-e-para-a-vida, assim como a leitura tem que ser. Sem trabalhar essa escrita vinculada com a vida, não vejo como é possível fazer com que o aluno valorize sua escrita e veja nela qualquer tipo de utilidade. Além disso, é preciso desvincular a ideia de escrita na escola de maniqueísta de que apenas a 'escrita padrão' serve para fins de registro escolar. A escrita do Facebook, as escritas cifradas dos diários pessoais, as múltiplas formas de escrita que nossa sociedade alimenta precisam ser trabalhadas pela e na escola também. Um dos maiores pecados da escola em relação à escrita, aliás, tem sido exatamente este: o de desprezar as múltiplas formas de escrita alimentadas na sociedade. (FERRAREZI JR, 2014, p. 83-84).

Ao que parece, a escola está indo na contramão dessas transformações e avanços ao insistir em manter a escrita estagnada e presa a um único padrão.

Além disso, esse discurso ostentador da homogeneidade, desenvolvido também pelas práticas de ensino, tem apagado, muitas vezes, a ideia da diversidade e da heterogeneidade da sociedade (MONTEAGUDO, 2011), sendo reforçado por meio dos atos de fala ${ }^{5}$ (AUSTIN, 1962) proferidos pelos professores em sala de aula.

A gramaticalidade vivenciada nesse espaço escolar acaba sendo

\footnotetext{
${ }^{5}$ Entendemos que os "atos de fala", termo proposto por Austin (1962), "não somente dizem sobre o mundo, mas fazem algo no mundo. Não descrevem a ação, praticam-na”. (OTTONI, 1998, p. 37). Ou seja, língua(gem), nesse sentido, significa ação.
} 
uma edificação que, uma vez enunciada, remete a um conjunto de possibilidades de utilização da língua, ou melhor, das práticas linguísticas. Essa gama de usos tem, ou deveria ter, a norma padrão como uma baliza, mas não como recurso para imobilizar a 'língua' numa relação diretamente proporcional a essa norma. (CORREA, 2014, p. 26).

Desse modo, a baliza que deveria ser a norma padrão acaba se tornando o foco principal do ensino do professor, o qual é incumbido de inculcar nos alunos, por meio de atos de fala repetidos, apenas esse uso, desconsiderando-se, então, as outras variedades existentes. Sendo assim, o que muitas vezes ocorre é que o uso acontece por ele mesmo, a gramática é desenvolvida por ela mesma, sem nenhum tipo de reflexão que faça com que o aluno perceba que essa é uma construção que acontece diariamente em nosso cotidiano.

Em outras palavras, o aluno precisa ter consciência de que a língua(gem) e a escrita que utilizamos em nosso dia a dia também fazem parte da realidade em que ele está inserido, também são expressas por meio das ações que ele desenvolve, e que a gramática, por mais que grande ênfase seja dada ao seu uso, não é a única forma de expressão existente.

Diante dessa inculcação, podemos notar que "discursos e práticas são performativos, ou seja, produzem efeitos que constroem o que alegam descrever em atos de fala ritualizados e iteráveis ${ }^{6}$ " (PINTO, 2012, p.173). Nesse sentido, as atitudes que são constantemente reiteradas em sala de aula, como a ideia de que há apenas um modo correto de falar e escrever, acabam tornando-se verdades "padronizadas" e, assim, passa-se a desconhecer e a se desconsiderar aquilo que se torna diferente do tido como o padrão a ser seguido.

Segundo Pinto (2012, p.171), com base em Mignolo (2003), esses "discursos hegemônicos sobre língua no Brasil" foram herdados da Modernidade colonial e atualmente têm enfrentado, "nas práticas identitárias contemporâneas, forças contrárias à sua estabilização, ao mesmo tempo em que a diferença colonial persiste [...]". Dessa forma, podemos observar que embates são produzidos mediante os atos de fala realizados na língua(gem). Tais atos de fala acabam sustentando, então, contradições e consensos, os quais serão brevemente discutidos a seguir.

\section{3) Entre algumas contradições e consensos: a escrita escolar}

Considerando os pontos acima elencados, vamos observar que certos aspectos e discursos desenvolvidos dentro dos muros escolares, mas não só dentro deles, passaram a ser considerados consensos (PINTO, 2012; 2014), já que, ao que parece, se tornaram espécies de verdades padronizadas e inquestionáveis mediante os atos de fala (AUSTIN, 1962) reiterados insistentemente no âmbito escolar.

\footnotetext{
${ }^{6}$ Iterabilidade entendida aqui como uma "propriedade que obriga o ato de fala a repetir o conhecido, necessariamente deslocando- o", como nos diz Pinto (2012, p. 173).
} 
Por meio desse termo - atos de fala - o filósofo Austin (1962) tinha como propósito discutir a realidade de ação da fala. No entendimento de Pinto (2006, p. 50), esse termo evidencia "a relação entre o que se diz e o que se faz - ou, mais acuradamente, o fato de que se diz fazendo, ou se faz dizendo".

A língua(gem) é vista, assim, de acordo com Pinto (2006, p.56), como "uma atividade construída pelos/as interlocutores/as, ou seja, é impossível discutir linguagem sem considerar o ato de linguagem, o ato de estar falando em si - a linguagem não é assim descrição do mundo, mas ação", isto é, ao produzirmos língua(gem), estamos produzindo ações, agindo por meio das palavras, de acordo com intenções próprias e apropriadas a certos contextos.

Essas ações constituídas por meio da língua(gem) ganham, a depender do contexto e do tempo, novas roupagens, novas adaptações, no entanto, mantêm nas bases de suas ideias as mesmas contradições (CORREA, 2014). Isto é, as ações se renovam no ato de dizer, mas a essência das ideias continua fortalecendo as contradições e os consensos. Ainda segundo Pinto (2014, p. 61), “os enunciados sobre língua no Brasil constroem consensos hegemônicos prévios, ao mesmo tempo em que estão expostos a novos deslocamentos".

Notamos, então, que os atos de fala são constantemente reiterados na sociedade, fazendo com que, por meio das repetições que vamos realizando, ideias sejam propagadas até o ponto em que passam a ser ritualizadas e tidas como verdades.

Além do mais, muitos dos discursos que circulam na escola são tomados como consensos, pois estão diretamente relacionados aos discursos hegemonicamente construídos e reiterados na sociedade. Esses discursos hegemônicos, de acordo com Pinto (2014, p. 62), "não são estáticos e nem soberanos sobre seus efeitos. Eles circulam em contradição uns com os outros, e experimentam tanto cumplicidade quanto resistência na sua atualidade local”.

Dessa forma, mediante tais discursos, forças de poder são adquiridas a fim de sustentar as hegemonias que circulam na escola e também socialmente. Sendo assim, podemos notar que discursos que condicionam, por exemplo, que há a supremacia da escrita em relação à fala, a inculcação de que há uma língua e uma escrita padrão a serem seguidas e de que quem domina a leitura e a escrita são consideradas pessoas letradas, são constantemente reafirmados em sala de aula, transformando-se em consensos e coerções.

A transformação desses discursos em fatos, muitas vezes, inquestionáveis se estrutura a partir do nosso próprio discurso que reitera os consensos em sala de aula, pois, inclusive nós, acreditamos nessas ideias, de que, de fato, a escrita é superior à fala e de que há um único padrão de língua e de escrita a serem seguidos, visto que o imaginário da uniformidade nos impede de enxergarmos a diferença. Sendo assim, ao tentarmos prezar a padronização, mascaramos a diversidade que se expressa, inclusive, em nós mesmos. Logo, pensando na escola, ofuscamos o desenvolvimento dos nossos alunos, os quais sofrem com as consequências do discurso ostentador de homogeneidades.

Escrever na escola significa, portanto, escrever para que o professor possa atribuir uma nota ou observar como anda o desenvolvimento do aluno em relação à 
escrita. Ou seja, restringe-se o texto ao espaço da sala de aula, em que não se sabe ao certo, se o professor será realmente o leitor daquele texto. Sendo este, então, usado apenas como um pretexto para se dizer de que modo os alunos estão escrevendo.

Ainda nesse sentido, quando a atividade de escrever se distancia muito da realidade vivenciada pelo aluno, surgem aí algumas dificuldades, pois, de fato, os alunos não percebem muita razão nessa ação de escrita, ou não são estimulados para que essa atividade se desenvolva de maneira satisfatória para ambas as partes. Assim, escrever para ter o texto de volta todo marcado, normalmente de vermelho, faz com que o aluno se sinta, muitas vezes, desmotivado, pois ele realmente acredita que não sabe escrever.

Esse modo de indicar os problemas ortográficos acontece inúmeras vezes com os alunos, fazendo com que se sintam desestimulados em aprender, e até mesmo em frequentar a escola. As ações, sendo assim, sejam elas negativas ou positivas, são insistentemente repetidas e fazem com que as internalizemos como verdades. No caso dos alunos, o fato de ouvirem que não sabem ler ou escrever ou que escrevem mal, os leva a acreditarem nessa suposta "verdade", imposta pelo professor, fazendo, então, com que haja o desestímulo e a crença do aluno de que escrever bem é saber muito além daquilo que ele já sabe ou então de que os atos de leitura e de escrita são processos desinteressantes a serem desenvolvidos.

Os atos de fala que circulam dentro da escola vão ao encontro do que diz Pinto (2012) a respeito da presença de três hegemonias que se desenvolvem em torno da língua no âmbito escolar, sendo elas:

A unidade linguística (variação monolíngue), a hierarquia escrita/oralidade e a correspondência linear língua/escrita/cognição. Essas hegemonias remetem a três modelos interpretativos da Modernidade colonial: o modelo romântico alemão de língua (uma língua, uma cultura, um povo), o modelo filológico de estudos das línguas (a escrita como fonte principal de conhecimento sobre as línguas) e o modelo evolucionista de escrita (a escrita como ícone de civilização). (PINTO, 2012, p. 174).

Notamos, assim, que, de fato, os discursos empregados hoje têm reflexos de "verdades" construídas socioculturalmente, as quais são sustentadas pelos atos de fala, e esses atos de fala, sustentados pelos professores em sala de aula, produzem efeitos significativos na língua(gem) que circula no âmbito escolar, efeitos que afetam diretamente os alunos, pois estes a compreendem como um processo complexo e distante de suas realidades, pois necessitam, segundo a escola, seguir a um padrão, a um modelo pré-estabelecido de escrever. Esses atos de fala são de caráter hegemônico, pois, a escrita e a fala desenvolvidas pelos alunos são distanciadas das práticas de escrita exigidas pela escola.

Segundo Britto (2003),

o estigma gramatical escolar corresponde a uma marca linguística negativa, a qual, apesar de ser de uso corrente, mesmo entre os falantes da norma culta, é objeto de correção sistemática. Este tipo de estigma resulta da opção normativa por parte de uma instância de poder linguístico (a escola, a norma canônica), que tende a condenar formas particulares de uso. (BRITTO, 2003, p. 38-39). 
Tendo em vista os modelos hegemônicos que são empregados na escola e na sociedade, de um modo geral, e diante de novos modelos de interação, podemos visualizar, por meio das abordagens de Pinto (2012), que duas contradições se estabelecem em relação a esses discursos hegemônicos sobre língua no Brasil. Sendo elas:

\begin{abstract}
A primeira contradição é operada por mudanças de projeto do sistema mundo/moderno/colonial: por um lado, a ênfase nos grandes centros mercadológicos atua em direção oposta ao controle nacionalista do modelo romântico alemão, na medida em que torna transnacional qualquer ação (econômica, social, cultural, política, linguística); por outro lado, as forças de subjetivação do consumismo (satisfação imediata, provisoriedade, insegurança e fragilidade) e da textualidade digital (rapidez, fragmentação, excesso e lacunas) atuam contra os modelos filológico e evolucionista, na medida em que ameaçam a estabilidade e a linearidade da escrita e sua articulação interpretativa hierárquica em instituições modernas (Estado, Escola, Universidade). [...] A segunda contradição é operada pela silenciosa e anônima perseverança do projeto moderno, a diferença colonial ${ }^{7}$ (MIGNOLO, 2003) que mantém a concepção temporal linear e, assim, os mesmos três modelos consolidados no século XVIII como parâmetros discursivos para se falar de língua. A persistência simbólica da escrita monolíngue padronizada como espaço privilegiado de expressão da cognição é prova dessa perseverança. A mídia e a instituição escolar, por exemplo, insistem que a oralidade e a diglossia são situações pré-civilizatórias. (PINTO, 2012, pp. 176-177 - grifos do autor).
\end{abstract}

Entendemos, dessa forma, que o controle nacionalista desenvolvido e perpetuado seja pelo Estado, pela escola e/ou pelas universidades, tem disputado espaço com os grandes centros mercadológicos, os quais ameaçam a estabilidade e a linearidade com que a escrita, e a língua(gem) de um modo geral, são vistas atualmente, mesmo mediante tal embate. Assim, a escrita monolíngue padronizada vai de encontro à perseverança do projeto moderno, o qual ocorre silenciosa e anonimamente, de modo que prevalece a ideia do monolinguismo e criam-se, então, as contradições.

Podemos observar, então, que os modos como têm se pensado a língua(gem) e a escrita atualmente, diante da entrada de novos padrões globalizados e multimidiatizados em diversos contextos, incluindo a escola, têm estado em conflito com as hegemonias que se estabelecem na sociedade, pondo à prova, desse modo, a visão única de língua(gem)e de escrita, e, até mesmo, do que seja ensinar ou falar a língua portuguesa. (PINTO, 2014).

Esse conflito entre os discursos presentes na realidade versus os discursos presentes no imaginário das pessoas tem abalado a centralidade da escola, pois "ela não é a única instância de articulação dessas ideias" (PINTO, 2014, p. 59). Essas ideias sobre língua atualmente têm sido questionadas e há uma fragmentação estrutural, em

\footnotetext{
${ }^{7}$ O termo "diferença colonial", abordado por Mignolo (2003), é entendido aqui como sendo a "insistência nos padrões de conhecimento e organização estabelecidos no contexto colonial e a consequente subalternização dos conhecimentos, das línguas, das culturas, das organizações sociais dos povos colonizados" (PINTO, 2014, p. 67). Nesse sentido, a permanência nesses padrões nos impede, de certa forma, de os questionarmos, fazendo, então, com que o poder, sustentado por esses padrões, permaneça ainda da contemporaneidade.
} 
que a forma de se compreender a língua(gem) e os modos de escrita se ampliaram. Sendo assim, mesmo que a escola ainda seja vista como o centro do ensino de línguas, segundo uma visão normativa e homogênea, não podemos ignorar que há a circulação de diversos discursos sobre língua também em outros espaços, os quais são tão significativos quanto a escola.

De acordo com Pinto (2014),

o ensino da língua materna no Brasil, fortemente influenciado por uma visão normativa que associa educação linguística com o ensino da chamada língua padrão (BRITTO, 2007), tem estado em conflito com discursos acadêmicos, com programas governamentais e com as demandas de estudantes (BAGNO; RANGEL, 2005). Mas essa centralidade não pode impedir que se observe a circulação de discursos sobre língua em outros espaços, tão impactantes quanto a escola, e em outros tempos, tão fundamentais para o estado atual da educação linguística no Brasil quanto decisões governamentais, formação de professores/as e pesquisas das últimas décadas. (PINTO, 2014, p. 61).

Esses novos espaços compreendem a língua por um viés diferenciado, pois são abertos à heterogeneidade e à diversidade de discursos que circulam insistentemente em nosso meio. Com esses discursos, então, podemos observar que as raízes que se criam e se desenvolvem ligam o passado e o presente, de modo que esses discursos apresentam algumas características: "de serem muito repetidos e de apresentarem grande capacidade de controle de seus efeitos e de sua própria reprodução, ou seja, são discursos hegemônicos". (PINTO, 2014, p. 60).

Nesse sentido, notamos que um embate se sustenta, pois são vetores de forças distintas que conduzem as noções de língua(gem) e de escrita para lados diferentes. De um lado, temos o consenso instaurado de que há uma língua e uma escrita únicas e, de outro, os novos modelos de interação. Esses novos modelos de interação nos conduzem para o questionamento dessa "verdade", utilizada nas práticas discursivas por meio dos atos de fala, visto que, atualmente, as opiniões fixas e fechadas não mais dão conta de atender às necessidades individuais e coletivas advindas com as transformações ocorridas.

Essa ideia vai ao encontro do que nos diz Pinto (2012), pois,

fora da escola a/o estudante precisa lidar com as consequências das mudanças das formas de interação (oralidade intensa, contato com diferentes variedades e línguas, textos curtos e rápidos, informações em constante mutação, produtos culturais transnacionais, estruturas linguísticas instrumentalizadas para projeção online - jogos, redes sociais, bate-papos etc.). Dentro da escola, a/o estudante precisa lidar com o modelo monolíngue e a precedência da escrita no desenvolvimento cognitivo. (PINTO, 2012, p.177).

Diante disso, o aluno entra num impasse, pois precisa adquirir hábitos diferenciados conforme os espaços em que circula. Para os alunos, isso tudo se torna muito confuso, pois precisam aprender a lidar com as diferentes situações e, como muitas vezes não lhes é ensinado que há mais de um modo de se expressar, falar ou escrever, e que uns são tidos como mais "corretos" e aceitos que outros, os alunos ficam 
perdidos e concordam que não sabem escrever, já que não dominam as regras da gramática normativa, discurso fortemente empregado e exigido na escola.

Podemos observar que as atividades e as práticas de escrita normalmente têm como foco a escrita escolar, ou seja, aquela pautada na decodificação do sistema escrito e ausente de discussões que vão ao encontro das necessidades e dos contextos vivenciados pelos alunos. Sendo assim, a escrita fica restrita à observação do modo como o aluno está escrevendo, bem como para que os problemas de ortografia sejam apontados, como já mencionamos.

Pensando no ensino escolar, podemos perceber também que ambos os vetores de forças se sustentam (escrita seguindo aos padrões da gramática normativa versus escrita desenvolvida pelo aluno), isto é, não há como abrirmos mão de um dos dois, ou seja, não há como abrirmos mão dos consensos já estabelecidos, mas também não há como vivermos por esses consensos, visto que nos são exigidas diversas posturas nos mais variados espaços por onde circulamos.

Desse modo, precisamos compreender que,

enquanto os estudantes têm que aprender, é claro, como conjugar verbos formar o plural de substantivos [...], eles também precisam aprender que há várias formas de fazer pedidos e expressar preferências, dependendo de quem fala, para quem, e em que circunstâncias. (KRAMSCH, 2014, p. 15).

Em outras palavras, notamos que há uma necessidade urgente de repensarmos os modos como são compreendidos os usos da escrita e da língua(gem) nos meios em que circulamos, além de haver uma "necessidade urgente de aprender a lidar com os alunos de hoje" (RAJAGOPALAN, 2003, p. 11), já que estão diante dessas novas formas de interação, a fim de que possamos descobrir seus anseios e atender às novas significações que se constroem em suas vidas.

Pinto (2013, p. 142) nos faz um alerta: "é preciso abrir, não os olhos ou os ouvidos, mas a imaginação para novas categorias provisórias, novos modelos sem enquadre; abrir e deixar aberta nossa forma de lidar com o português no mundo de hoje". Ou seja, há a necessidade de nos despirmos do passado para encararmos o presente e o futuro de modo mais aberto, mais sintonizado com o que de fato vem acontecendo, seja na escola ou na própria sociedade, em relação ao modo de se compreender as características atribuídas à escrita, e a outras formas de língua(gem).

Parece fundamental, portanto, compreendermos como atualmente a língua(gem) e a escrita vêm sendo vistas na e pela sociedade, e principalmente na escola, pois,

a internet e as formas eletrônicas de comunicação têm tirado espaço das formas convencionais e previsíveis de comunicação oferecidas pela literatura impressa, gramáticas e dicionários, e aberto um caminho para a criatividade, agência e inovação, mas têm também aumentado a incerteza e a ambiguidade semiótica. Para resumir, elas têm mudado o nosso significado de comunicação, língua e cultura. (KRAMSCH, 2014, p. 10).

Nesse sentido, as transformações vivenciadas na e pela sociedade precisam ser assumidas e aceitas, de modo que equívocos e contradições possam ser evitados e novos 
espaços e formas como a escrita e a língua(gem) se apresentam possam ser conquistados.

\section{4) Palavras Finais...}

Como pudemos perceber anteriormente, alguns consensos e contradições se fazem presentes em sala de aula, reforçando, desse modo, algumas hegemonias advindas de séculos atrás. Uma das formas de enfrentarmos a permanência dessas ideologias coloniais e dos paradoxos diante da centralidade dos "modelos interpretativos modernos - nacionalista, filológico e evolucionista", de acordo com Pinto (2014, p.72), é nos aproximarmos da "polifonia recombinante" a que está exposta nossa "língua nacional". Essa polifonia vai de encontro, principalmente, à ideologia monolíngue que se estabelece no Brasil. Aproximarmo-nos da "polifonia recombinante" e entendermos a língua como polissistemas (MONTEAGUDO, 2011), mesmo sendo um grande desafio, será uma maneira de tentarmos compreender do que e como, afinal, está sendo constituída a língua portuguesa aqui no Brasil atualmente.

Podemos perceber, portanto, que o cenário que nos é apresentado em relação ao desenvolvimento e à evolução do entendimento de língua(gem) e de escrita é bastante complexo e desafiador, pois estamos diante de uma síntese paradoxal em que os discursos hegemônicos, herdados do passado histórico, enfrentam forças contrárias diante das práticas identitárias contemporâneas, as quais têm se configurado atualmente. (PINTO, 2014).

Dessa forma, a ideologia monolíngue tem encontrado resistência diante da polifonia recombinante a que está exposta a língua nacional, bem como os novos modelos de interação têm encontrado dificuldade para conquistar espaço em meio ao discurso tradicional de uma língua e uma escrita únicas.

Observamos, assim, que o âmbito escolar ainda tem muito a repensar e a refletir no quesito ensino e aprendizagem da escrita e da língua(gem), de modo que, novas atitudes precisam ser tomadas, a fim de que caminhos mais emancipatórios possam ser criados mediante as novas interações, os novos suportes e os novos modos de escrita que visualizamos atualmente. Esse passo, no entanto, precisa ser dado conjuntamente, com o intuito de que todos os envolvidos com a educação possam ser beneficiados.

\section{Referências}

AUSTIN, John L. How to do Things with Words, Oxford, Oxford University Press, 1962.

BRASIL. Secretaria de Educação Fundamental. Parâmetros Curriculares Nacionais (5 a $8^{a}$ séries). Brasília: MEC/SEF. 1998.

BRITTO, Luiz Percival Leme. Contra o consenso: cultura escrita, educação e participação. Campina, SP: Mercado de Letras, 2003. 
CORREA, Djane Antonucci. Práticas linguísticas e ensino de língua: variáveis políticas. In: CORREA, Djane Antonucci (Org.). Política linguística e ensino de língua.

Campinas, SP: Pontes Editores, 2014.

FARACO, Carlos Alberto. Norma culta brasileira: desatando alguns nós. São Paulo: Parábola Editorial, 2008.

FERRAREZI JR., Celso. Pedagogia do silenciamento: a escola brasileira e o ensino de língua materna. 1.ed. São Paulo: Parábola Editorial, 2014.

ILARI, Rodolfo; BASSO, Renato. O português da gente: a língua que estudamos a língua que falamos. 1. Ed., $1^{\text {a }}$ reimpressão. São Paulo: Contexto, 2007.

KRAMSCH, Claire. Por que os professores de língua estrangeira precisam ter uma perspectiva multilíngue e o que isto significa para a sua prática de ensino. In.: CORREA, Djane Antonucci (Org.). Política Linguística e Ensino de Língua. Campinas: Editora Pontes, 2014. p. 11-20.

Why foreing language teachers need to have a multilingual Outlook and what that means for their teaching practice. Revista Muitas Vozes. Ponta Grossa, v. 1, n. 2, p. 181-188, 2012.

MONTEAGUDO, Henrique. Variação e norma linguística: subsídios para uma (re)visão. In.: LAGARES, Xoán; BAGNO, Marcos (Org.). Políticas da norma e conflitos linguísticos. São Paulo: Parábola Editorial, 2011. p. 15-48.

OTTONI, Paulo Roberto. Visão performativa da linguagem. Campinas, SP: Editora Unicamp, 1998.

PINTO, Joana Plaza. A Pragmática. In: MUSSALIN, Fernanda; BENTES, Anna Christina. (Orgs.). Introdução à linguística: domínios e fronteiras. 5 ed. v. 2. São Paulo: Cortez, 2006. p. 47-68.

. Hegemonias, contradições em discursos sobre língua no Brasil. In.: CORREA, Djane Antonucci (Org.). Política Linguística e Ensino de Língua. Campinas: Editora Pontes, 2014. p. 61-74.

Modernidade e diferença colonial nos discursos hegemônicos sobre língua no Brasil. Muitas Vozes, Ponta Grossa, v. 1, n. 2, p. 171-180, 2012.

Prefiguração identitária e hierarquias linguísticas na invenção do português. In.: MOITA LOPES, Luiz Paulo da (Org.). Português no século XXI: cenário geopolítico e sociolinguístico. São Paulo: Parábola Editorial, 2013.

PORCHEDDU, Alba. Zygmunt Bauman: Entrevista sobre educação. Desafios Pedagogicos e Modernidade Líquida. Tradução: Neide Luzia de Rezende e Marcello Bulgarelli. Cadernos de Pesquisa, v. 39, n. 137, maio/ago. 2009.

RAJAGOPALAN, Kanavillil. Política linguística: do que é que se trata, afinal? In.: NICOLAIDES, Christine, et al. Política e Políticas Linguísticas. Campinas - SP: Pontes Editores, 2013. 
Por uma linguística crítica: linguagem, identidade e a questão de ética. São Paulo: Parábola Editorial, 2003. p. 29-36 e 71-76.

SIGNORINI, Inês. (Org.) Língua(gem) e identidade: elementos para uma discussão no campo aplicado. Campinas - SP: Mercado de Letras; São Paulo: Fapesp, 1998.

SILVA, Rosa Virgínia Mattos e. Ensaios para uma sócio-história do português brasileiro. São Paulo: Parábola Editorial, 2004. 